\title{
Symbolic creativity in play activity: a critique on playthings from daily life objects to toys
}

\author{
Nilüfer Talu \\ Department of Industrial Design, Faculty of Architecture, Izmir Institute of Technology, İmir, Turkey
}

\begin{abstract}
Play is an essential activity for children's development. Children play with daily life objects as well as toys. Daily life with its various objects and practices provides a real freedom for discovery and selfrealization. Children celebrate this value through symbolic creativity that flourishes in various play practices, such as symbolic object use, storytelling, animation in special modes of virtualization and actualization, construction with everyday mathematics and puzzling for order in chaos. The study examines a girl's play activities with daily life things and waste materials between 6 and 8 years of ages. Finally, the study emphasizes that: (1) symbolic creativity is necessary for children's self-realization and accordingly for their well-being and (2) toys must be selected carefully to stimulate children's ability to imagine, create and produce.
\end{abstract}

\section{ARTICLE HISTORY}

Received 26 July 2016

Accepted 12 May 2017

\section{KEYWORDS}

Symbolic creativity; play activity; playthings; toys; child development

\section{Introduction to the critique on playthings and toys}

Children play with objects, whether they are called toys or not. Here, the question is what kind of objects contribute to children's symbolic creativity. What is the role of various material objects as playthings in symbolic creativity? Although they are silent, material objects around children function as key operators to let children produce on their own. Miller (2010) calls this interaction 'the humility of things', in which daily life objects help people learn how to act appropriately in everyday routines (p. 53).

Children need to be free to follow appropriate practices. Symbolic creativity needs the realm of freedom. Feeling free and having free time for play may be the only necessities for these activities. In these terms, toys or playthings should neither become the dominant parts managing the play nor dictate the way/pattern of play. In this context, we need to consider that the free play time without adult control is more important than having too many toys or designed materials. Much discourse has criticized toys, as they can be harmful as dominant interferences. Although toys and playthings have a place at all playgrounds in the modern world, Ariel emphasizes that free playtime is a self-evident necessity and should be free from adult interference. Even in educational settings, children should be left to their own devices (Ariel, 2002, pp. 117-118). Barthes says (1957/1980), '[...] toys literally prefigure the world of adult functions and obviously cannot but 
prepare the child to accept them all [...]' (p. 53). Cohen (1993), however, records detrimental parental interference when he observes, '[...] the toys parents choose to buy for their children’ (p. 61). In Barthes' (1957/1980) words:

However, faced with this world of faithful and complicated objects, the child can only identify himself as owner, as user, never as creator; he does not invent the world, he uses it: there are prepared for him actions without adventure, without wonder, without joy. (pp. 53-54)

Worse, they are the children of a culture, built to look for the 'wow climax - the moment of peak spectacle and maximum emotional impact in an act' that is not about telling stories but about putting on a show, as Jenkins (2006) expresses (p. 11). These toys belong to the world of design and marketing, not to play with but to collect perhaps for profit (Birtles, 2010).

This seems an important reality for this study. The goal of this study is, in fact, to investigate this reality and the other many questions that arise connected with daily life practices and things in child play.

\section{The method of the study}

This research paper questions the kind of objects that contribute to children's symbolic creativity or rather the role of playthings in symbolic creativity. In the research, a girl's free play activities are observed in relation with various playthings to detect symbolic creativity that leads to self-realization. The main focus is placed on the girl's play activities to demonstrate the characteristics of a complex concept called symbolic creativity in a cultural, philosophical, psychological, and sociological context. Based on a long-term observation of a girl's play activities, the research can be regarded as a single case study. However, while the main method can be described as single case study, the sub-method is more like an observation conducted with ethnographic fieldwork techniques such as using major dimensions of descriptive observation and concrete language. A case is characterized by wholeness of the parts in a tendency towards equilibrium (Wanderstoep \& Johnston, 2009, p. 209) that could only be understood in a certain context (Gillham, 2000 , p. 1). The study does not solely focus on culture or experience, moreover on interdependence of major dimensions which are mainly playthings and play activities in daily life context. All case studies mainly focus on two elements which are evidence and theory (Gillham, 2000, p. 3, 21). The storytelling and physical artefacts that are created by the girl are accepted as evidences. They are explained with theories to make sense of the context. The physical creation and storytelling noted during the girl's free play activities are linked not only to certain play theories but also to sociological, psychological, behavioral, philosophical, and cultural views addressing the question of the research. The case is presented in a narrative form according to the chronology of observations.

\subsection{Selection of the case}

The research covers an observation period of three years in which a child aged from 6 to 8 years old has been studied. The selection of this particular age period is important in that it is believed to be the time when the middle stage of childhood begins, the school life starts, and daily life activities of children are planned in order to manage busy schedules, 
homework, and tasks. Acquiring some valued skills and establishing good connections with other children are the important issues. School, teachers, parents, coaches, and peer groups play central roles in the setting of daily life activities (Bartko, 2008, p. 89). When the necessary conditions are provided for a free environment, children's play activities reach their most complex form in terms of creativity and imagination in the middle childhood period. Children are better at expressing their feelings and emotions using language. They are very good at integrating play activities spontaneously into their daily life routines and experiences. They are successful performers of drama and fantasy plays. Playing with everything and telling imaginative stories are prevalent daily activities. They have more improved skills associated with craft knowledge. They are eager to construct material things along with everyday mathematics and puzzle instinct. In this period, nearly most of them typically tend to collect and keep small things such as tokens, cards, buttons, toy parts, etc. that indicate their curiosity for material interactions. Materiality of things is the enthusiastic subject for discovery. Therefore, the study focuses on this abundant period to question playthings in the context of daily life and creativity. Thus, the case is selected mainly on the criterion of typicality. But the physical constructions of the girl, studied in the last part, make the case unique.

\subsection{Ethical concerns}

The research is conducted with the consideration of doing no harm to the informant (Piper \& Simons, 2005, p. 56). As the researcher is a close relative of the girl, being around her was very natural. They have been very familiar to each other. So the presence of the researcher does not influence the girl's behaviors or interfere with her usual daily routine of playing activities. The photos are taken as snap-shots not only for the sake of the research but also for storing them in family albums to record her childhood times. In order to protect the privacy of the informant, the study changes the girl's name as Deniz. All informants, especially the ones being a subject of a long-term single observation, deserve to get benefits from the research in concern. (Spradley, 1980, p. 24). The girl is informed about the study verbally after the observation has been completed and conclusions are drawn. She expresses naïvely how she is satisfied as being a part of a study, saying that 'Am I a famous person now?'

\subsection{The level of participation}

Observation has been conducted at regular intervals at least three times a month for three years except for summer months. It involves various routines and different time periods of the day. The researcher maintains a moderate participation. Researcher reads her stories, helps her tidy her room, and cooks a cake with her. The researcher witnesses that all of daily life activities are naturally combined with play notion involving symbolic object use, storytelling or puzzling instinct. Therefore, the researcher observes her not only while playing with the toys but also having breakfast, lunch and dinner, doing homework, organizing toys, and helping the housework. For example, the researcher records that she plays with a group of pens, naming them Speaking Pen Sisters while doing her homework. As another example, she uses clothespins to construct railway lines while helping the laundry. While having considerable involvement with the daily life activities at home, 
observer maintains a low profile during the girl's play activities. Observer wants to avoid involvement, unless the girl wants to play together. If the researcher is somehow required to, the researcher just tries to keep up with the girl's performance and tries to play in a passive manner. This moderate level of involvement not only lets the researcher remain objective but also provides a free playground for the girl.

\subsection{About the informant}

Being an only child, she was born into a middle class family. Her parents both have active working lives with their undergraduate and graduate degrees. They live in a decent apartment in an upper middle class neighborhood of İzmir, known as one of the most modern cities in Turkey. She attends to a private school where the students are encouraged for critical thinking and creative projects. She takes piano lessons and sings in school choir. She has a variety of toys involving generic, constructive, and collectible ones, and she has the access to some basic materials that can be used in some basic crafting. She has her own room, but still she enjoys taking the advantage of every corner of the apartment as different playgrounds. She is also very eager to search through drawers, boxes, and wardrobes for discovery and adventure. During the day, she spends some time in her wardrobe playing happily among clothes by herself.

\subsection{Recording the observation}

Recording the observation is mainly based on taking field notes and photos. Field notes have been taken as condensed version such as abbreviations, half sentences, key words, major actions and events either during or immediately after the observation. Then, as soon as possible the notes have been transformed into an expanded account in concrete language. The researcher tries to be objective by giving as much specific details as possible without making generalizations, summarizing and using the abstract language of social sciences. The phrases uttered by the girl have been recorded according to verbatim principle and written as concrete language (Spradley, 1980, p. 67, 68, 70). For example:

After breakfast, she comes to her own room and starts searching for her doll, Yağmur. She calls: 'Yağmur where are you?' She opens the door and looks inside the wardrobe. Yağmur is in the wardrobe. Apart from Yağmur the doll, she sees her soft dog inside the wardrobe and takes both of them out. Throwing them away, she runs to her mom's bedroom and takes her mom's hair brush and a few hair clips in front of the mirror. Then, she returns back to her own room quickly and starts speaking with the doll seriously saying: 'It is 9 o'clock. Let's brush your hair then have breakfast. Then you will go to school.' She brushes the doll's hair carefully and puts hair pins on it. She puts a hair pin in her pocket. She leaves the doll on the carpet and runs to the bedroom of her mom again. She comes back with a medium size tin box full of hair curlers to her room [...]. (6 years oldJanuary-Weekday-10 am)

\subsection{Major dimensions, phases and theorizing}

The case is based on descriptive observation. It is conducted along with a list of major dimensions below (Spradley, 1980, p. 78). 
(1) Space: Home as domestic space.

(2) Actor: A girl.

(3) Activity: Play activity such as fantasy play, pretending play, and constructive play

(4) Object: All physical things that function for play activities such as various toys (from generic toys to collectibles), daily life objects (from teacups to a wardrobe), and waste materials (from plastic packagings to cardboard boxes in various geometrical forms).

(5) Act: Actions in the play activity such as brushing the doll's hair, gluing a button on a plastic box, using a teacup to substitute a bathtub for the doll, telling a story on/about the toys, etc.

(6) Event: Daily life routines as a set of activities such as eating, learning, sleeping, cleaning, etc. that all have potentials to be integrated with play activities.

(7) Goal: Symbolic creativity is achieved through discourse production, metarepresentation and basic creation/construction of objects.

(8) Feeling: Self-realization.

(9) Time: Middle childhood (6-8 years of age) as the most complex period of child's play.

The phases of descriptive observation are general, focused, and selective (Spradley, 1980, p. 34). The study starts with a wide general observation examining all dimensions. Then, it is pursued with focused observation and finally it is narrowed into selective observation. Each of the phases is nearly equivalent to a year-long observation period. The observations are transformed into narrative format according to the chronology of the phases from the perspective of the research question.

The first phase/general observation (6 years of age): the study examines all of the dimensions in daily life context. Chapter 3. Everyday life as a realm of freedom: From domestic furniture and goods to all daily life things around us is based on this phase. The study determines the statements: (1) play activity is an integral part of everyday life and (2) everything can function as a toy. The statements along with the related field notes are influenced by various theories related to culture, art, philosophy, fantasy, and human behavior. The observation is compared with the writings of Willis (1990/2002) (symbolic creativity in daily life), Baudelaire (1863/1986) (curiosity of child for daily life), Wohlwend (2009) (undirected play with materials in unexpected ways), Lewis (1950/1994) (undirected play for discovery and fantasy) and Hegel (1818-1829/1975) (the mode of self-production in external things).

The second phase/focused observation (seven years of age): the study focuses on especially two dimensions: activity as pretending play and objects as daily life things. This phase is chiefly reflected in the chapter, 3.1. Play with daily life things: symbolic object use. The chapter underlines the statement: daily life things are very beneficial playthings for symbolic creativity. The statement is supported with the examples of symbolic object use and storytelling performances of the girl. The chapter is mainly justified with play theories on drama and pretending with references to the writings of Ariel (2002) (the use of language and symbols), Smith (2002) (symbolic object use and metarepresentation), Fein, Darling, and Groth (2002) (mental thinking), Courtney (1990) (as if thinking-as if acting), and Chazan (2002) (pretending as symbolic thought).

The last phase/selective observation (eight years of age): the study has been narrowed with selective observation. The study focuses on mainly two dimensions: objects as physical artefacts made up of waste materials and acts as actions such as collecting and adding 
parts to each other to create meaningful objects. She constructs many objects with waste materials, creates characters and tells stories using decontextualized language. The chapter 4, Play with waste materials deals with this period. The statement of the chapter: creative activities with materials around is a fundamental part of daily life. Realm of freedom, which is related with daily life, is emphasized as a necessary context for this statement. The chapter is explained with the references to Keane (2009) (self-realization as human labor in material thing), Marx (1844/1992) (human being as free being), Sayers (2003) (creative activity for human being) and Hegel (1807/1977) (the outer as the expression of the inner). The study refers to Ginsburg's (2006) everyday mathematics (organization of objects according to number, shape, and pattern) and Danesi's (2002) puzzle instinct (search for order in chaos) to comprehend the motivation enabling the girl to create certain objects/things with some household waste materials. So, this chapter is detailed with philosophical and material culture perspectives and also social and psychological play theories.

\section{Everyday life as a realm of freedom: from domestic furniture and goods to all daily life things around us}

It is well known that daily life is a creative realm and a resource for symbolic creativity. Paul Willis (1990/2002) positions symbolic creativity in daily life as something that '[...] has to be done every day, that which is not extra but essential to ensure the daily production and reproduction of human existence' (p. 283). Baudelaire (1863/1986), in his famous 'The Painter of Modern Life', celebrated everyday life as inspiration for artistic production (pp. 1-40). According to Baudelaire, to call inspiration and motivate creativity, the artist focuses on everything in everyday life in the state of newness like children always do: 'The child sees everything in a state of newness; he is always drunk. Nothing more resembles what we call inspiration than the delight with which a child absorbs form and colour' (Baudelaire, 1863-1986, p. 8). Baudelaire (1863/1986) considers the artist as a man-child, a genius who orders the accumulated mass of raw material for self-expression, with deep curiosity for everything, 'whatever it be, whether a face or a landscape, gilding, colours, shimmering stuffs or the magic of physical beauty [...]' (p. 8).

Anyone who spends time with children can see how they play with what they have at that moment: any equipment, any material, any everyday life object such as a pen, a box, a stone, a stool, a table, a drawer or a wardrobe. A line on the ground, a hole in a tree trunk, a bird in the sky, a texture on a stone can be inspiration for any play. Children creatively challenge the direction of play, combining various practices, materials, and modes, often in unexpected ways and contexts (Wohlwend, 2009, p. 61).

While playing freely without any kind of interference, having just an intimate space can be sufficient to activate mental play. This play comes true while dreaming in an introverted space such as under a table, behind a door, under a bed or behind a curtain. Such spaces, where children feel the most comfortable, safe, and free to imagine, work as a moderator between the domains of fantasy and reality. The famous masterpiece of Lewis's (1950/ 1994) The lion, the witch, and the wardrobe is an example of this mental play activity. Four school children transit to the magical world of Narnia and many adventures 
through the back of a wardrobe. The empty rooms, the row of closed doors all are material environments encouraging children's exploration and play. Free playtime without adult interference is the only necessity (pp. 10-13).

When children are observed in daily life, it is recorded that many of them really prefer to stay in such spaces for long hours, especially in the closets. When I asked why, Deniz answers simply, 'I want to stay in the wardrobe because it is my play.' It is really free play. Deniz prefers playing in the corner, a very small space between the wall and her wardrobe, for long hours. She calls this space 'my small corner', sits on a big cushion, and brings her soft animals and generic baby toys to this space. She wants to cover it with a curtain. It is a kind of activity to search mental spheres in a phenomenological sense. In other words, it is a mental journey to the inner world, allowing the exercise of independence, that requires contemplation. Children need to be free and undirected in order to be creative and imaginative. Here, the intention is to emphasize the role of material objects/environment in these creative practices.

In these terms, a play activity may not require interaction with a material object that is designed exactly as a toy. Play activity accepts many kinds of material objects, whether they are designed to be a toy or created to be something else. Playing with toys/material objects fullfils either ' $[\ldots]$ a basic human need to connect with an object [...]' or a need to use an object to construct something else that is discursive and meaningful (Jackson, 2001, pp. 139-145). Playing with toys should enhance children's manipulative and cognitive skills and give them the opportunity to manipulate the exterior. Hegel (1818-1829/ 1975) states that:

Even a child's first impulse involves this practical alteration of external things; a boy throws stones into the river and now marvels at the circles drawn in the water as an effect in which he gains an intuition of something that is his own doing. This need runs through the most diversiform phenomena up to that mode of self-production in external things which is present in the work of art. (p. 31)

\subsection{Play with daily life things: symbolic object use}

Drama plays, especially in the pre-school and school-aged developmental period, are the most fruitful play activities to seek symbolic creativity. Make-believe play is the most well-known drama play. The initial function of pretending is certainly defined as 'the communication of meaning' (Howes, Unger, \& Matheson, 1992, p. 6). In Ariel's words:

Make-believe play is a kind of mental activity [...] This mental activity includes the following mental operations, performed simultaneously: evoking some mental images [...]; animating these mental images [...]; verbalizing the mental operation of animating [...], or identifying some perceptible entity in the immediate play environment [...] with it. (Ariel, 2002, p. 7)

Drama works with three elements: (1) storytelling as specific modes of writing, (2) symbolic object use as devising, and (3) acting/performing (McCullough, 1998, p. 172). These fantasy plays are composed of two components: symbolic object-use and complex scripts and roles (Smith, 2002, p. 129). Deniz keeps an empty plastic bottle and says: 'This is my new born baby. She is sleepy. Please be quiet.' In another 
example, keeping a piece of a tree branch, she says, 'I am a fairy and this is my fairy wand. If you steal it, you will see that it will not work for you.' As many female children do, she holds her baby doll with great care as if she is a good mother. Once, during a journey in the car, Deniz says, 'I am not here.' This shows the duality of thinking and 'as if acting and how she performs as imaginer rather than a player. Whenever Deniz is left free, all of these existences become raw materials to be transformed into something functional and symbolic; pretending an object is something else, like substituting a cup for a hippopotamus' bath (Figure 1). She used to substitute an armchair for a cooker. She would put some objects under the armchair, saying, 'Are you hungry? My delicious cake will be ready in 30 minutes.' After one or two minutes, she would take the object that she had placed under the armchair with extreme care, asking, 'Who wants to eat warm cake?' Children manipulate objects with action and auditory modes including sound effects, speeches, and gestures. These pretense forms involving wishes, current impressions and expectations encourage the coordination of the inner world with the outer and the dream world with reality. Freud (1908/2013) interprets that:

The opposite of play is not what is serious but what is real. In spite of all the emotion with which he cathects his world of play, the child distinguishes it quite well from reality; and he likes to link his imagined objects and situations to the tangible and visible things of the real world. This linking is all that differentiates the child's 'play' from 'phantasying'. (p. 4)

Children organize social observations into coherent patterns while pretending play, attributing mental thinking and emotional feeling to inanimate things (Fein et al., 2002, p. 143). Smith draws a parallel between the cognitive benefits of this play and the theory of mind, similar to many studies of the 1990s. The theory of mind involves representation and requires understanding of others' knowledge and beliefs. For example, 'This is a box' means the representation of the real object - primary representation; 'this box is a house' is decoupled from reality - secondary representation. It is recorded as the metarepresentation 'a representation of the primary representation', and understanding it in this context, $\mathrm{X}$ believes that this box is a house
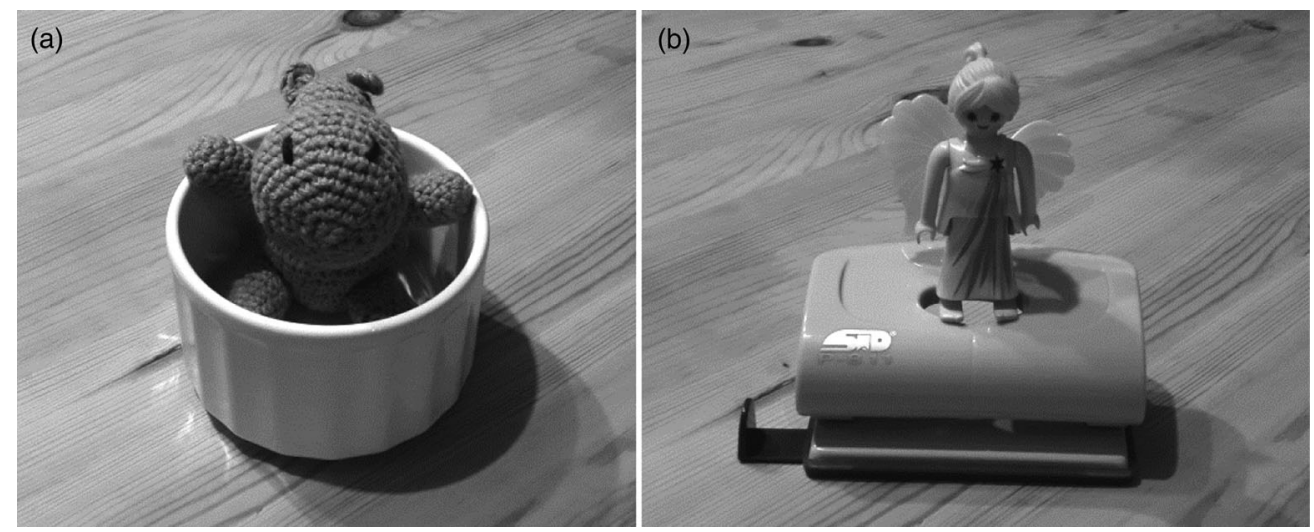

Figure 1. (a) Substituting a cup for a hippopotamus' bath and (b) substituting a hole punch for a space ship. 
(Smith, 2002, pp. 132-134). In these terms, children have the ability of interpretation and transformation. The duality of 'as if thinking and 'as if acting blurs the border between knowing and believing (Courtney, 1990, p. 35). Meaning is constructed at the intersection of knowing and believing within the mode of persuasion. People communicate this condition mutually through dialogue. Dramatic processes are operative at four cognitive levels:

1. Has a store of existing knowledge and belief (a state of being). 2. Presupposes the virtual existence of the other ('knowing how to be'). 3. Communicates what s/he knows or believes to another (communication). 4. Transforms what is received from the other ('knowing how to do'). (Courtney, 1990, p. 37)

Transformation is the basic cognitive level based on the practical modes of the virtualization and the actualization.

Pretend play's complexity and multifunctional nature originate in their contribution to the use of language and symbols. For Ariel (2002), 'The term semiotic system refers to a system of signs and symbols. Make-believe play is a semiotic system' (p. 15). The language of make-believe play has its own characteristics. Make-believe sentences sound absurd. The ad hoc combination of different signifiers and references to unconventional signifieds are the main characteristics of this language (Ariel, 2002, pp. 24-27). For example, a box can represent many things, from a baby to a kettle to a hospital. The combination of signifiers can change immediately. Another typical characteristic of make-believe language is transformation. In this operation, any kind of signifier can refer to any signified. For example, Deniz says, 'I am the big sister of this baby' and immediately changes her voice 'I am her mum.' Research witnesses how she is simultaneously in and out of play (Figure 2).

'The capacity to pretend' means 'the capacity for symbolic thought' (Chazan, 2002 , p. 200). The study records many representational objects - toy canoes from folded paper, dolls made of plastic bottles, a magic wand from a wooden stick, a creature from a ball of paper, a ship from a coffee table are observed as sufficient materials for playthings.

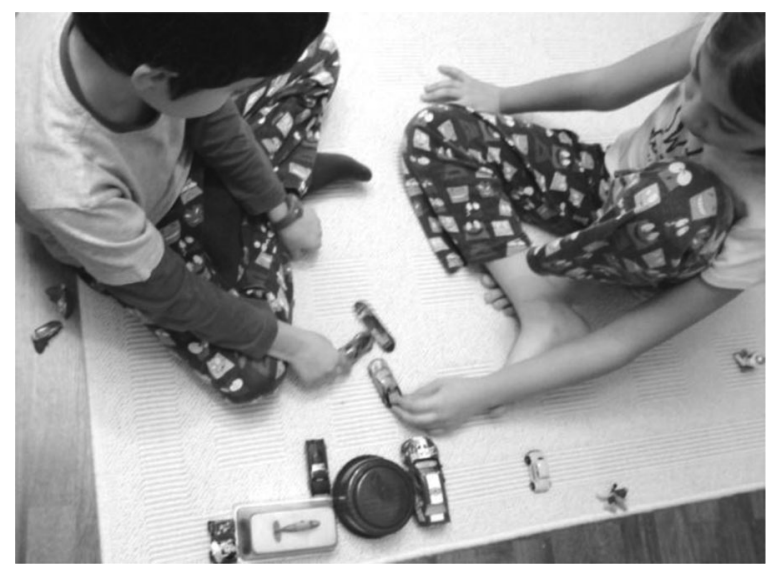

Figure 2. Construction of a chokey for living cars with cooking cups. 


\section{Play with waste materials}

Through construction, representation and many other creative methods, children play with waste materials. Packages of consumer products or various package boxes are rich materials of an undefined play activity.

\subsection{The realm of freedom}

The human being produces his own object, in other words, the expression of himself, through the materials provided by the external world. Keane (2009) says: '[...] self-realization depends on the subject's being able to read the traces of human labour in the material thing' (p. 197). It is observed that Deniz is quite interested in the collection of everyday life things to play with and modify. Boxes, bottles, glasses, ropes, wires, lids, broken little parts and little parts with missing bodies are some of these collected items (Figure 3). She plays with them by substituting them for playthings. Examining and modifying broken parts, joining them together, keeping the parts with avid interest are all play activities, as well. Various materials, ropes, plastic glasses, buttons, broken parts, textile parts, detergent boxes, bottles, etc. are all considered as playthings to produce something meaningful. Production through the world of objects is in the human being's intrinsic nature. Marx (1844/ 1992) interprets this relation perfectly:

Man is a species-being, not only because he practically and theoretically makes the species both his own and those of other things - his object, but also - and this is simply another way of saying the same thing - because he looks upon himself as the present, living species, because he looks upon himself as a universal and therefore free being. (p. 327)

Here, Marx emphasizes that the human being produces an objective world; therefore, he is a species-being. He duplicates himself in the external world through free creative activity where he sees himself in a world (of objects) that he has created. If he lacks objects, the duplication of himself, he not only feels unhappy but also discontented and without meaning. In this condition, he does not manifest himself to be anything and becomes

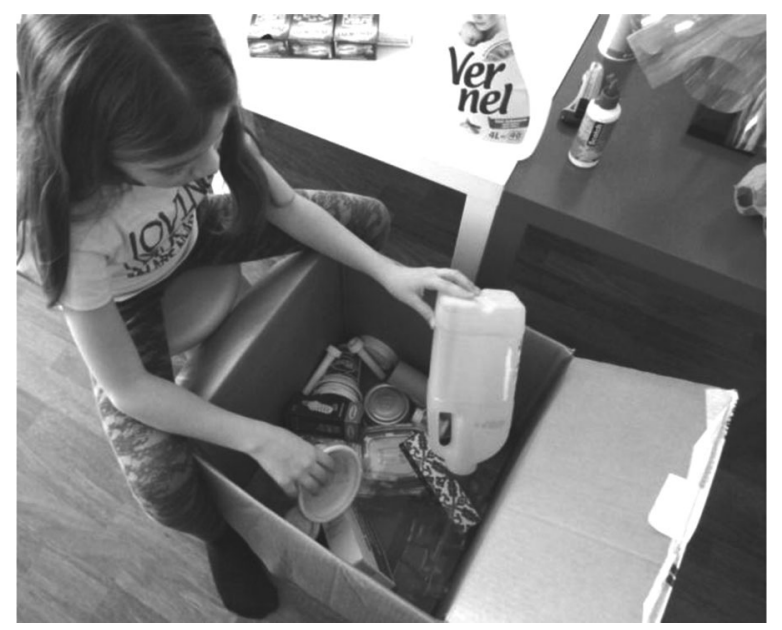

Figure 3. The realm of freedom: collection of daily life things as if puzzle pieces. 
an animal. In these terms, he is not free. 'Creative activity', which is fundamental for the human being, is considered as 'the realm of freedom' (Sayers, 2003, p. 113). The material object he produces belongs to his intrinsic nature. Hegel (1807/1977) explains that '[...] the inner, and actuality the outer; and their relation produces the law that the outer is the expression of the inner' (p. 160). He questions what shape each has: 'The inner as such must have an outer being and a shape, just as much as the outer as such; for it is an object, or is itself posited in the form of being, and as present for observation' (Hegel, 1807-1977, p. 160).

\subsection{Constructive play with waste materials}

All constructive plays, such as building blocks and play dough, are based on production/ construction/creation of something meaningful. In construction plays, two basic methods are well known. While one is inductive, that is, based on addition of some parts to the others, the other is deductive, that is, based on subtracting/carving parts from a whole material. Children learn about everyday mathematics and physics by considering or finding a particular order. Everyday mathematics refers to the impulse of children to organize objects according to number, shape, and pattern (Ginsburg, 2006, pp. 145165). They try to coordinate a piece of material object as a part of whole, or they try to find the meaning of a part, like a word in the context of a language. Constructive plays are largely analytical interests for possible artifacts.

Deniz is seen to focus on waste material things, mostly empty cardboard boxes of various sizes, as if they are geometrical building blocks. She constructs certain figures that are meaningful and familiar in a sense similar to geometrical dissection and arrangement of parts in a puzzling language or picture. Puzzle instinct and everyday mathematics appear as basic concepts to understand construction play. Danesi (2002) tells us in his Puzzle Instinct that the human being searches for order in chaos, and that is the central motivating force of the puzzle instinct (p. 111). For Danesi (2002), 'Incredibly, even in the domain of chaos, the human mind finds ways of making sense of things [...] order arose out of chaos' (p. 110, 111). The girl's construction of a certain figure can be easily understood within this context. To clarify, as represented in Table 1, the construction of a simple phrase such as 'Children like cartoons' explains the arrangement of the words in puzzling language to create a meaning. Various daily life things function as if they are parts of a puzzle or building blocks. The key practices of the first phase are search, find and compose in puzzle instinct. The big parts mostly refer to the main bodies; small parts, to the details. When Deniz finds a bottle lid, she says, 'It is one of the eyes of my robot, which was lost.' Or when she meets a linear part, she says, 'It is the leg of my doll.' It is observed that things are perceived independently from their existing functions. Instead of by their previous functions, things are focused by their dimensions, proportions, colors, and textures. Deniz searches for the appropriate parts and adds them to each other in the manner of everyday mathematics. Similarly, she is curious about the possible combinations of the parts with the others. She focuses on the details of the construction. She says, 'I can glue them to each other', 'I can bind it with a rope', or 'I need to cut this part' (Table 2). Her first construction is 'Mr. Grey' (Table 2, mid-right), who consists of 12 parts. His main body is a detergent box, head is a small medicine box, legs are 
Table 1. Symbolic creativity as discourse and construction: arrangement of the words and the objects.

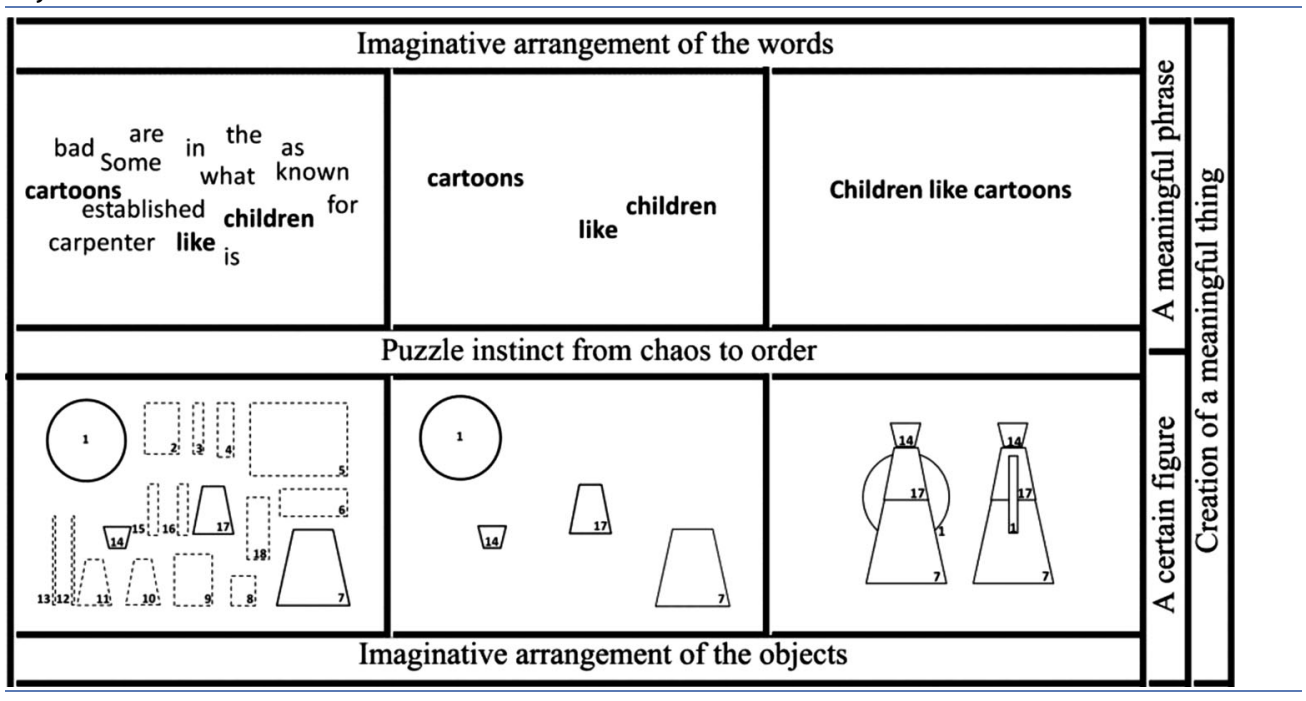

Table 2. Construction and drama plays: build something and tell a story. Cross-Eyed-Nice-Alien (Top Right), Mr. Grey (Middle Line-Right).

\begin{tabular}{|c|c|c|c|}
\hline \multicolumn{3}{|c|}{ Construction play } & Drama play \\
\hline Search & Find/Select & Compose/Combine & Animate \\
\hline 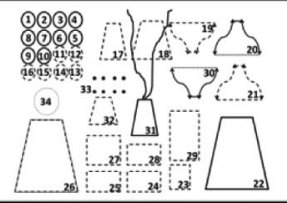 & 3.. $\left\{\begin{array}{r}r^{309} \\
r^{200}\end{array}\right.$ & & \\
\hline 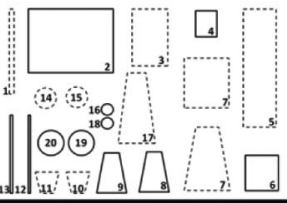 & $\left.\right|_{13} \|_{12}^{120(10)}$ & $\begin{array}{l}\text { (19) (20) } \\
\text { (20, }\end{array}$ & \\
\hline $\begin{array}{l}\text { Free dialectic between the } \\
\text { subject and the objects, } \\
\text { the realm of freedom, } \\
\text { spontaneity, no textual } \\
\text { reference, discovery, } \\
\text { and chaos }\end{array}$ & $\begin{array}{l}\text { Focusing on the selected } \\
\text { objects as forms, } \\
\text { dimensions, } \\
\text { proportions, colours, } \\
\text { textures, etc. }\end{array}$ & $\begin{array}{l}\text { Everyday mathematics } \\
\text { as geometrical dissections, } \\
\text { (adding, subtracting, etc.), } \\
\text { modification of the objects, } \\
\text { (bending, cutting, } \\
\text { distorting, piercing, etc.) } \\
\text { order and construction }\end{array}$ & $\begin{array}{l}\text { Drama, animating, } \\
\text { character creation, } \\
\text { naming, story telling, } \\
\text { and decontextualized } \\
\text { language use }\end{array}$ \\
\hline
\end{tabular}

plastic glasses, and arms are flexible plastic linear bands from the back of her shoes. On his main body's surface are two circular milk bottle lids and a square biscuit wrapper. His mouth is a curvilinear part of a red milk bottle lid. His eyes are green fruit juice lids placed asymmetrically and are little or big according to the proportions of the head, which makes him cute with an always smiling mouth. His arms are flexible and thin (Figure 4). 

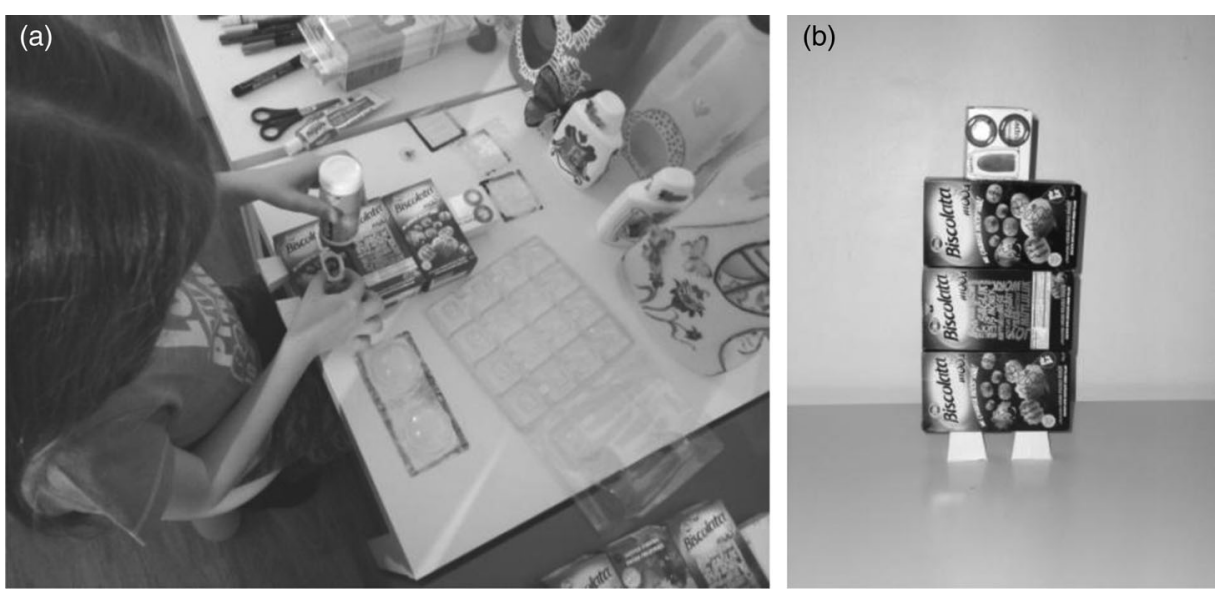

Figure 4. (a) Construction of the parts as craft work and (b) Mr. Biscolata.

\subsection{Drama play with waste materials}

Deniz constructs many figures based on simple everyday mathematics. After the construction, she names her figures and spontaneously tells stories. The characters are Mr. Grey, Mr. Biscolata, Sweet Toblerone, Cassette Robot, Cross Eyed Nice Alien, etc. Animating with verbal constructions is the phase through which she plays with words and statements. When she finished the construction of Mr. Grey, for example, she began to construct a subjective set of sentences about him, exactly in the context of decontextualized language. Typical sentences: 'Mr. Grey is a good friend... He is running now. He smiles at me. He gets angry ... He is reckless and flexible. Poor you! He is very strong. Do not say something bad to him! There is a bomb behind him.' When other children's storytelling is examined, it is seen that this observation is similar to many writings. Their storytelling mostly lacks coherence and some components of a good story: setting (title, characters, time, and place), theme (goal or problem), plot episodes (events), and resolution (solution, ending statement, and longrange consequences). They construct fragmented story sequences (Fein et al., 2002, pp. 142-144). While managing many different roles within the story sequences, children interweave dreams and reality, create good and bad characters, and produce statements. Especially young children's story sequences are based on a 'decontextualized discourse' that is removed from here and now as scenarios, stories, narratives, explanations, and monologues (Nicolopoulou, Mcdowell, \& Brockmeyer, 2006, p. 126).

\section{Conclusion: critique on toys}

In light of the above information and observations, it is demonstrated that play is a necessary activity for all children to contribute to their inner worlds, where they construct a bridge between subjective experience and material objects through symbolic creativity. The study concludes that symbolic creativity is observed in play activities along with production, representation and drama forms. The practices are varied and include constructing, organizing, installing, substituting, telling, animating, and performing. Waste material 
things are also recorded as motivators of construction and puzzle instinct. They provide craft production without any pattern.

In many discourses, toys are deservedly criticized for their part in consumption culture (Cross \& Gregory, 2005; Hilton, 1996; Lauwaert, 2009; TNLG, 1996; Townsend, 2011). Even if many useful toys are also in the market, many are simply proponents for consumption. For example, collectibles; these objects stay as material things of fascination. They are produced in a field according to the principle of style, being 'artifacts in their own contexts'. Their styles serve to refer solely to the relationship between themselves within a given object domain (Miller, 1987, p. 127). These material objects relate to each other in a system of meaning rather than to the subjects. For Miller (1987), individual artifacts covered by style and fashion gain their effect from their comparative lack of abstraction (p. 127).

According to this study, value is recorded in the relation between daily life things and children and in the practice of play, such as construction or representation. Therefore, toys, as design products, must be developed to meet children's needs as follows: (1) the practice: play and (2) the interaction between children and 'materiality of thingness'. The craft concept perfectly fits these conditions. Maintenance is the most important feature of the craft concept involving discovery (Sennett, 2008). Here, symbolic creativity and value are created at the interaction of children and 'materiality of thingness' rather than in the individual product itself. It is necessary to cite from Attfield (2000): 'the materiality of thingness that resides at the real world' as the rediscovery of things to find authenticity and originality (p. 60).

Under the hegemony of consumption culture, children can aspire to possess self-valued individual products. Parents should consider their children's basic needs rather than see them as little consumers (Kapur, 2005, p. 23). For the opportunity of symbolic creativity, toys should be either simple, such as generic toys, or in flexible and abstract forms as material entities. Parents need to avoid toys that tell their children everything, leaving nothing to imagine.

\section{Disclosure statement}

No potential conflict of interest was reported by the author.

\section{Notes on contributor}

Niliufer Talu, BArch, MSc, PhD, Teaches at the Department of Industrial Design and the Department of Architecture, Izmir Institute of Technology, Izmir, Turkey. Received her MS (2002) in Industrial Design and her PhD (2008) in Architecture from the same university. Her main research interests lie in modernity, consumption, and material culture theories in the relevance of design.

\section{References}

Ariel, S. (2002). Children's imaginative play: A visit to wonderland. Westport, CT: Greenwood Press. Attfield, J. (2000). Wild things: The material culture of everyday life. Oxford: Berg. Barthes, R. (1957/1980). Mythologies. (A. Lavers, Trans.). New York, NY: Hill and Wang. Bartko, W. T. (2008). The contexts and significance of children's everyday experiences and activities: A commentary. In C. R. Cooper, C. G. Coll, W. T. Bartko, H. M. Davis, \& C. Chatman (Eds.), 
Developmental pathways through middle childhood: Rethinking contexts and diversity as resources (pp. 89-95). Mahwah, NJ: Lawrence Erlbaum.

Baudelaire, C. (1863/1986). The painter of modern life (J. Mayne, Trans.). In J. Mayne (Ed.), The painter of modern life and other essays. (pp. 1-40). New York, NY: Da Capo Press.

Birtles, J. (2010). Cult collectibles from Barbie to Gaga. The Spectator, 312(9472), 36. Academic OneFile, edsgcl.221189188.

Chazan, S. E. (2002). Profiles of play: Assessing and observing structure and process in play therapy. London: Jessica Kingsley.

Cohen, D. (1993). Development of play. Florence, KY: Routledge.

Courtney, R. (1990). Drama and intelligence: A cognitive theory. Montreal: McQueen's University Press.

Cross, G., \& Gregory, S. (2005). Japan, the U.S. and the globalization of children's consumer culture. Journal of Social History, 38(4), 873-890. Project MUSE, edspmu.S152718970540873X.

Danesi, M. (2002). Puzzle instinct: The meaning of puzzles in human life. Bloomington: Indiana Uiversity Press.

Fein, G. G., Darling, L. D., \& Groth, L. A. (2002). Replica toys, stories, and a functional theory of mind. In R. W. Mitchell (Ed.), Pretending and imagination in animals and children (pp. 142153). West Nyack: Cambridge University Press.

Freud, S. (1908/2013). Creative writers and daydreaming. (J. Strachey, Trans.). In S. A. Figueira, E. S. Person, \& P. Fonagy (Eds.), IPA: The contemporary Freud: Turning points and critical issues series: On Freud's creative writers and day-dreaming (pp. 1-13). London: Karnac Books.

Gillham, B. (2000). Case study research methods. London: Continuum.

Ginsburg, H. P. (2006). Mathematical play and playful mathematics: A guide for early education. In D. G. Singer, R. M. Golinkoff, \& K. Hirsh-Pasek (Eds.), Play=Learning: How play motivates and enhances children's cognitive and social-emotional growth (pp. 145-168). Oxford: Oxford University Press.

Hegel, G. W. F. (1807/1977). Phenomenology of spirit. (A. V. Miller, Trans.). Oxford: Clarendon Press.

Hegel, G. W. F. (1818-1829/1975). Aesthetics: Lectures on fine art. (T. M. Knox, Trans.). Oxford: Clarendon Press.

Hilton, M. (1996). Manufacturing make-believe: Notes on the toy and media industry for children. In M. Hilton (Ed.), Potent fictions: Children's literacy and the challenge of popular culture (pp. 19-46). London: Routledge.

Howes, C., Unger, O., \& Matheson, C. C. (1992). The collaborative construction of pretend: Social pretend play functions. Albany: State University of New York Press.

Jackson, K. M. (2001). From control to adaptation: America's toy story. The Journal of American \& Comparative Culture, 24 (1-2), 139-145. doi:10.1111/j.1537-4726.2001.2401_139.x

Jenkins, H. (2006). Wow climax: Tracing the emotional impact of popular culture. New York, NY: NYU Press.

Kapur, J. (2005). Coining for capital: Movies, marketing and the transformation of childhood. New Brunswick, NJ: Rutgers University Press.

Keane, W. (2009). Subjects and objects. In C. Tilley \& W. Keane (Eds.), Handbook of material culture (pp. 197-202). London: Sage.

Lauwaert, M. (2009). Place of play: Toys and digital cultures. Amsterdam: Amsterdam University Press.

Lewis, C. S. (1950/1994). The lion, the witch, and the wardrobe. New York, NY: Harper Colins.

Marx, K. (1844/1992). Economic and philosophical manuscripts. (R. Livingstone \& G. Bentone, Trans.) In R. Livingstone \& G. Bentone (Eds.), Early writings (pp. 279-400). Harmondsworth: Penguin Classics.

McCullough, C. (1998). Building a dramatic vocabulary. In D. Hornbrook (Ed.), On the subject of drama (pp. 169-184). London: Routledge.

Miller, D. (1987). Material culture and mass consumption. New York, NY: Basil Blackwell.

Miller, D. (2010). Stuff. Cambridge: Polity Press. 
Nicolopoulou, A., Mcdowell, J., \& Brockmeyer, C. (2006). Narrative play and emergent literacy: Storytelling and story-acting meet journal writing. In D. G. Singer, R. M. Golinkoff, \& K. Hirsh-Pasek (Eds.), Play=learning: How play motivates and enhances children's cognitive and social-emotional growth (pp. 124-144). Cary, NC: Oxford University Press.

Piper, H., \& Simons, H. (2005). Ethical responsibility in social research. In B. Somekh \& C. Lewin (Eds.), Research methods in the social sciences (pp. 56-63). London: Sage.

Sayers, S. (2003). Creative activity and alienation in Hegel and Marx. Historical Materialism, 11(1), 107-128. doi:10.1163/156920603321624758

Sennett, R. (2008). The craftsman. New Haven, CT: Yale University Press.

Smith, P. K. (2002). Pretend play, metarepresentation and theory of mind. In R. W. Mitchell (Ed.), Pretending and imagination in animals and children (pp. 129-141). West Nyack: Cambridge University Press.

Spradley, J. P. (1980). Participant observation. New York, NY: Holt, Rinehart and Winston.

The New London Group. (1996). A pedagogy of multiliteracies: Designing social futures. Harward Educational Review, 66(1), 60-92. Academic OneFile, edsgcl.18560441.

Townsend, M. (2011). Why Ken is the new babe-magnet in toyland. Bloomberg Businessweek, 4216, 21-22. MasterFILE Complete, 58117624.

Wanderstoep, S. W., \& Johnston, D. D. (2009). Research methods for everyday life. Blending qualitative and quantitative approaches. San Francisco, CA: Jossey-Bass.

Willis, P. (1990/2002). Symbolic creativity. In B. Highmore (Ed.), The everyday life reader (pp. 282292). London: Routledge.

Wohlwend, K. E. (2009). Damsels in discourse: Girls consuming and producing identity texts through Disney princess play. Reading Research Quarterly, 44(1), 57-83. doi:10.1598/RRQ.44. 1.3 